\title{
Peptide Self-Assemblies for Drug Delivery
}

Diana M. Leite ${ }^{1}$, Eugen Barbu ${ }^{1}$, Geoff J. Pilkington ${ }^{1}$, Aikaterini Lalatsa ${ }^{\star}$

${ }^{1}$ Department of Pharmaceutics, School of Pharmacy and Biomedical Sciences, University of Portsmouth, St Michael's Building, White Swan Road, Portsmouth PO1 2DT, UK

"Corresponding author: Dr Aikaterini Lalatsa, Lecturer in Pharmaceutics, School of Pharmacy and Biomedical Sciences, St Michael's Building, University of Portsmouth, White Swan Road, Portsmouth, P01 2Dt, Tel.: +44 0239284 3929; E-mail address: katerina.lalatsa@port.ac.uk 


\section{Abstract}

Peptide amphiphiles (PAs), are novel engineered biomaterials able to self-assemble into supramolecular systems with applications in delivery across challenging biological barriers and intracellularly particularly in the field of brain diseases, regenerative medicine and cancer. PAs are amino-acid block co-polymers, with a peptide backbone composed usually of 8-30 amino acids, a hydrophilic block formed by polar amino acids and an apolar block which usually entails either apolar or aromatic amino acids and alkyl, acyl or aryl lipidic tails and in some cases a spacer or a conjugated targeting moiety. Alteration in the balance between the hydrophilic and hydrophobic blocks result in a range of supramolecular structures that are usually stabilised by hydrophobic, electrostatic, $\beta$-sheet hydrogen bonds and $\pi-\pi$ stacking interactions. In an aqueous environment, the final size, shape and interfacial curvature of the PA is a result from the complex interplay of all interactions. Lanreotide is the first PA to be licensed for the treatment of acromegaly and neuroendocrine tumours as a hydrogel administered subcutaneously, while a number of other PAs are undergoing preclinical development. This review discusses PAs architecture fundamentals that govern their self-assembly into supramolecular systems for applications in drug delivery.

Keywords: peptide amphiphiles, nanofibers, self-assembly, driving forces, drug delivery

Table of Contents (TOC) Graphic 


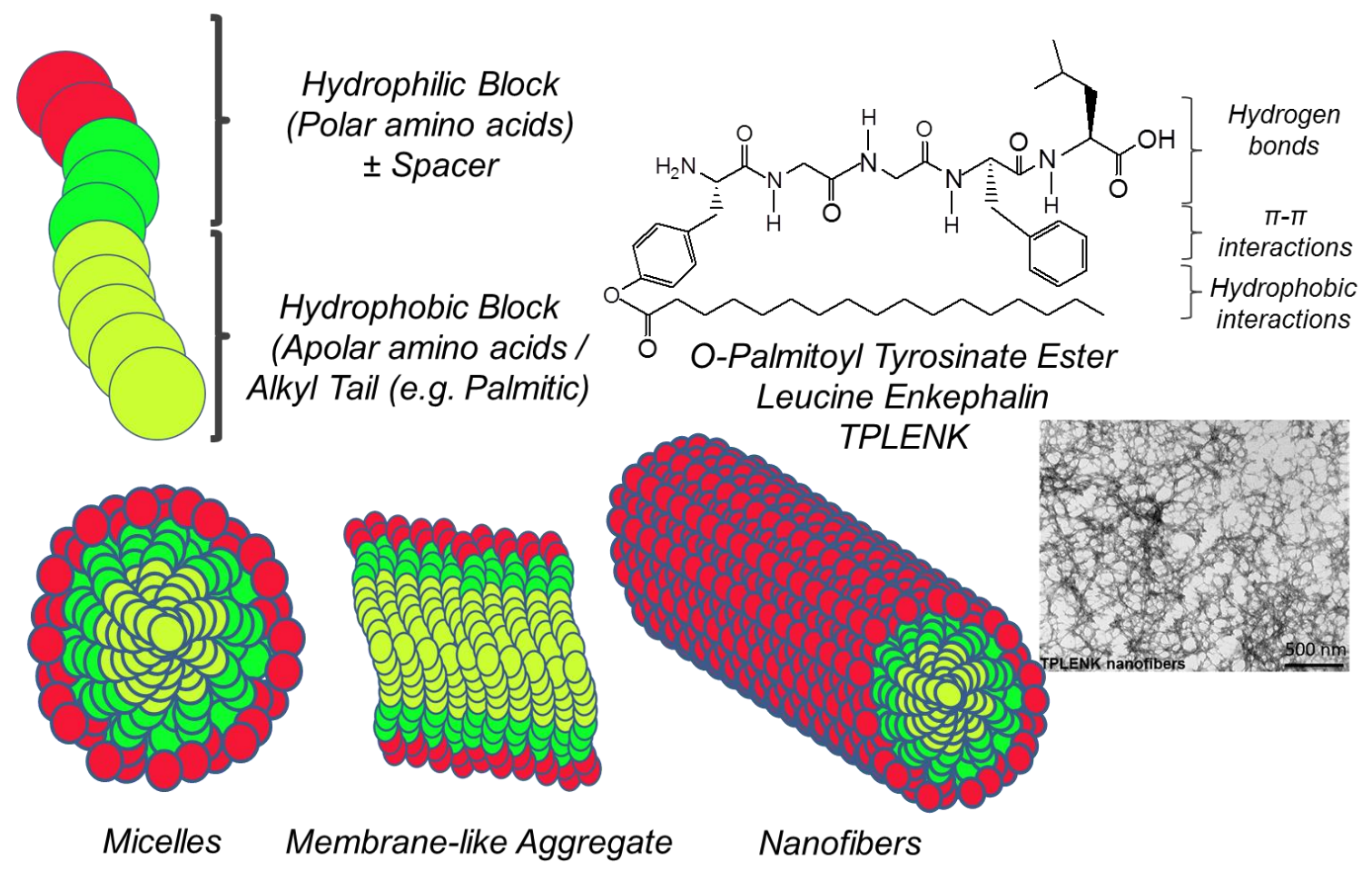

\section{Introduction}


The current pressures on the pharmaceutical market, conferred by need for lower healthcare costs, increasing generic substitution and increased demand for efficacy and safety [1], have resulted into a recent surge in interest from pharmaceutical and biotechnology companies to peptides, proteins and antibodies. These biopharmaceuticals possess high potency and selectivity, which combined with their confinement mostly to extracellular targets, confer a favourable risk benefit ratio over small molecular weight APIs [2].

Peptides have not always been the most popular candidates for drugs [3]. Peptides were thought to be expensive and complicated to manufacture, had exceptionally short half-lives resulting in chronic administration being costly and patient unfriendly particularly due to the need for parenteral administration as oral bioavailability remains for most peptides below $10 \%$ [4].

However, peptides biodegrade into non-toxic or low toxicity metabolites while they possess minimal potential for drug-drug interactions and low immunogenicity compared to larger proteins enjoying an over $20 \%$ probability of regulatory approval, a rate that is double that of small molecules [3]. Compared to proteins and antibodies, peptides have the ability to penetrate further into tissues owing to their small size and are less immunogenic than recombinant proteins and antibodies [2]. The manufacturing costs for therapeutic peptides are lower possessing higher activity per unit mass, greater stability, and safe degradation products minimising the risk of systemic toxicity [2].

Over the past decades, supramolecular assembly of biomacromolecules has been used a powerful toolbox for creating new and functional material. Peptide 
amphiphiles (PAs) are a class of synthetic peptides modified with hydrophobic, lipid or lipid-like tails that have been used for bottom-up fabrication of biomaterials [5]. PAs combine the structural features of amphiphillic surface active molecules known to self-assemble into a variety of nanostructures [5] or as functional coatings on preformed nanostructures [6]. PAs can be exemplified by a hydrophobic tail, a linker, a spacer and a hydrophobic head and alterations in these basic structural segments can control the resulting morphology (micelles, vesicles, nanotubes, nanofibers, nanosheets), surface chemistry and even function. Peptide amphiphiles assemble into a variety of structures mediated by electrostatic interactions between charged amino acids, hydrogen binding, $\pi-\pi$ stacking interactions and hydrophobic associations [7, 8]. Hence, many PAs are currently explored as nanomaterials for various applications including regenerative medicine [9], gene [10] and drug delivery [11]. This review will focus on the parameters affecting supramolecular engineering of peptide amphiphiles as their chemical structure and forces driving the selfassembly and the applications of peptide amphiphiles in the field of drug delivery.

\section{Amino acids: The Molecular Building Blocks}

Whereas synthetic polymers are usually formed by the polymerization of a one to three building blocks, proteins are composed of 20 different amino acids [7]. This high number of building blocks and the peptide sequence can provide a wide diversity of molecular characteristics. The amino acid building blocks are categorised in non-polar, polar and others [8, 12]. Non-polar amino acids are divided into two groups: aliphatic [alanine $(\mathrm{A})$, leucine $(\mathrm{L})$, valine $(\mathrm{V})$, isoleucine $(\mathrm{I})$ and methionine $(\mathrm{M})$ ] and aromatic [tyrosine $(\mathrm{Y})$, phenylalanine $(\mathrm{F})$ and tryptophan $(\mathrm{W})$ ] which may contribute to hydrophobic clustering. The aliphatic residues favour hydrophobic 
interactions, while the aromatic amino acids can also be involved in $\pi-\pi$ stacking that have been increasingly recognized as relevant in the peptide self-assembly [8]. The polar, uncharged amino acids, serine $(\mathrm{S})$, threonine $(\mathrm{T})$, asparagine $(\mathrm{N})$, glutamine $(\mathrm{Q})$, are involved in hydrogen bonding interactions through $-\mathrm{OH}(\mathrm{S}, \mathrm{T})$ or $-\mathrm{CONH}(\mathrm{N}$, Q) groups [8]. However, there are five charged amino acids (positive charged: histidine $(H$, pKa 6.5), lysine $(K, p K a ~ 10)$, arginine $(R$, pKa 12), and negatively charged: aspartic acid (D, pKa 4.4), glutamic acid (E, pKa 4.4)) able to establish electrostatic interactions that aid in forming assemblies (exploiting oppositely charged groups) or in preventing assembly (exploiting electrostatic repulsion) [8]. From the remaining building, glycine and proline are strand directing residues. Glycine introduces a high level of flexibility comparing to other amino acids, mainly due to the lack of steric hindrance induced by the side chain $[13,14]$. Proline, on the other hand, confers a conformational rigidity to the peptide due to the locked conformation caused by the side chain being covalently linked to the amino terminus [8] and is commonly found in turns or at the beginning of an a-helix and in the edge strands of a $\beta$-sheet. Cysteine, due to the presence of the reactive thiol group in its side chain can be chemically modified (e.g. via maleimides) or via disulphide bonds intermolecularly. Furthermore, tyrosine, serine and threonine, hydroxyl groupcontaining amino acids, are also used for chemical or enzymatic modification $[8,11$, 15]. Finally, the peptide backbone itself can confer stability via hydrogen bonds.

Even peptides as short as dipeptides can orderly arrange into a variety of different structures and particularly, dipeptides containing at least one phenylalanine. Diphenylalanine has been shown to produce rigid nanotubes with a Young's elastic modulus of 19GPa via m-stacking [16, 17]. Fmoc-diphenylalalanine peptides forms 
hollow peptide tubes $(50-1000 \mathrm{~nm}$ in diameter $)$ able to form hydrogels spontaneously [18].

\section{Peptide amphiphile blocks}

With amino-acid block co-polymers, the peptide backbone composed of 8-30 amino acid long with the polar amino acids form the hydrophilic block and the apolar amino acids and grafted alkyl, acyl or aryl lipidic tails forming the hydrophobic block [5, 8, 12, 19-21] (Figure 1A). In some cases, it is possible to also be composed of a linker or a spacer in between the two blocks if needed such as polyethylene glycol (2KDa) [22] or glycine spacers [23]. The hydrophobic blocks are tunable containing, usually, 3-9 apolar amino acids or 12-16 carbons in the acyl or alkyl chain [12]. As for all amphiphiles the critical aggregation concentration is critical to their stability [24] with this value ranging between nanomolar $[15,22,25]$ to micromolar concentrations [26, 27] depending on the nature of the hydrophobic block. This is an important consideration if in vivo drug delivery applications where dilution with biological fluids is inevitable. Additionally, the aqueous solubility of the PA and, consequently its aggregation in water, is also greatly dependent on the hydrophobic block with larger tail lengths resulting in enhancement in aggregation propensity [5]. A strong ability to form intermolecular hydrogen bonds between the hydrophobic amino acid results commonly in $\beta$-sheets that are critical for the stability and morphology of the assemblies $[5,28]$. On the other hand, the hydrophilic block consists primarily of charged amino acids and can confer some $\mathrm{pH}$-responsiveness to the assemblies [5, 28], which can be used to control the morphology of the assembly [29-32]. For example, a coiled-coil a-helix with leucine at position $\mathrm{d}$ and glutamic acid residues at positions e of an abcdef heptad leucine zipper (SGDLENEVAQLEREVRSLEDEAAE 
LEQKVSRLKNEIEDLEAE) forms homodimeric coiled-coils which are destabilised in basic solutions [29]. Incorporating glutamic acid and lysine pairs at the e and $\mathrm{g}$ positions to stabilise the coiled-coil of leucine zippers (KIAALKQKIASLKQEIDALEYENDALEQ and KIRALKAKNAHLKQEIAALEQEIAALE

Q) resulted in nanosized fibres that unwind into random coils in response to an increase in ionic strength as these charges were screened, destabilising the helixhelix interaction [30-32]. By designing an amino acid sequence that resembled both that of a leucine-zipper coiled-coil and that of a b-hairpin (AcYGCVAALETKIAALETKKAALETIAALC-NH2), a system was created able to change the conformation from a-helix to b-hairpin when heated, while also consequently forming a gel [30-32].

Peptide amphiphile structure can be modified by incorporation of peptide sequences known to be substrates for proteases, kinases or phosphatases to elicit enzyme responsiveness of the final assembly [33, 34]. Similarly, introducing signalling epitopes such as the RGDS sequence [19, 35-37] or IKVAV [38, 39] which can confer certain properties such as cell adhesion or neural adhesion, migration and neurite growth respectively.

Thus, by carefully engineering the structure of peptide amphiphiles, it is possible to tailor the morphology, stability, and function of the resulting supramolecular assemblies.

\section{Forces driving the self-assembly of PAs}


PAs self-assembly is driven by hydrophobic interactions, hydrogen bonding, $\pi-\pi$ stacking and electrostatic interactions (Figure 1A) adding to the diversity of engineered assemblies.

\subsection{Hydrophobic Interactions}

Hydrophobic interactions occurring in the non-polar amino acid region of the peptide associated with a lipidic tail result in the formation of a hydrophobic core usually present within nanofibers in water [24]. These attractive forces are a direct result of the interfacial tension of the lipidic tail-water interface [40-46]. Hydrophobic interactions are less geometrically constrained compared to electrostatic interactions [28] and the tail length is an important engineering parameter for stable peptide amphiphiles. Gore et al. using a model collagen peptide headgroup investigated the effect of the number of tails and temperature on the self-assembly of collagen mimetic PAs [40]. Amphiphiles containing a single or double tail of $\mathrm{C} 12$ to $\mathrm{C} 14$ formed spherical micelles but PAs with longer tails aggregated into disc-like micelles that stacked up to form a strand-like structure. Only peptides with longer tails, C18 and C20, were affected, in terms of aggregate secondary structure from helical which is restored by the increase of temperature. PAs with hydrophobic alkyl chains with different lengths (C9, C11, C13 and C15) and a hydrophilic headgroup of VRGDV (Val-Arg-Gly-Asp-Val) formed nanofibers at a neutral $\mathrm{pH}$ of 7 [42]. However, at increased $\mathrm{pH}$, the PAs with shorter tails, $\mathrm{C} 9$ and $\mathrm{C} 11$, assembled into micelles, instead of fibers, with a width of $\sim 30 \mathrm{~nm}$ [42]. Thus, increasing the length of the hydrophobic tail results in tightly packed due to stronger hydrophobic interactions driving the self-assembly process providing stability to $\mathrm{pH}$ changes. Altering the combination of non-polar amino acid residues within the PA sequence can also 
confer steric topologies that can affect the self-assembly process. Substituting the Phe $(F)$ residues with non-polar residues of different size $(G, A, V, L$, and I) in model peptides (FEFEFKFK)2 alters the co-operative binding between different hydrophobic areas of the peptide chains in formation of b-sheets [41]. Finally, manipulation of the hydrophobic region of the Pas by introduction of phospholipids, namely 1-palmitoyl-2hydroxy-sn-glycero-3-phosphocholine, can modulate the mechanical properties of the assemblies and elicit hydrogels when the lipid constitutes the $20 \%$ of the total molecular weight formed by non-covalent hydrophobic interactions [44, 47].

Table 1: Driving forces involved in self-assembly. Modified from [48]

\section{Type of interaction Strength $(\mathrm{kJ} / \mathrm{mol}) \quad$ Properties}

Electrostatic $\quad 50-300 \quad$ Short ranged, Non-selective

Coordination binding 50-200 Short ranged, Directional

Hydrogen bonding 5-120 Long ranged, Selective, Directional

$\pi-\pi$ Stacking $\quad 0-50 \quad$ Short ranged, Directional

Solvophobic Depends on solvent type Short ranged, Little directional constraint

van der Waals $\quad<5 \quad$ Short ranged, Non-directional, Non-selective

Covalent $\quad 350 \quad$ Short ranged, Irreversible 


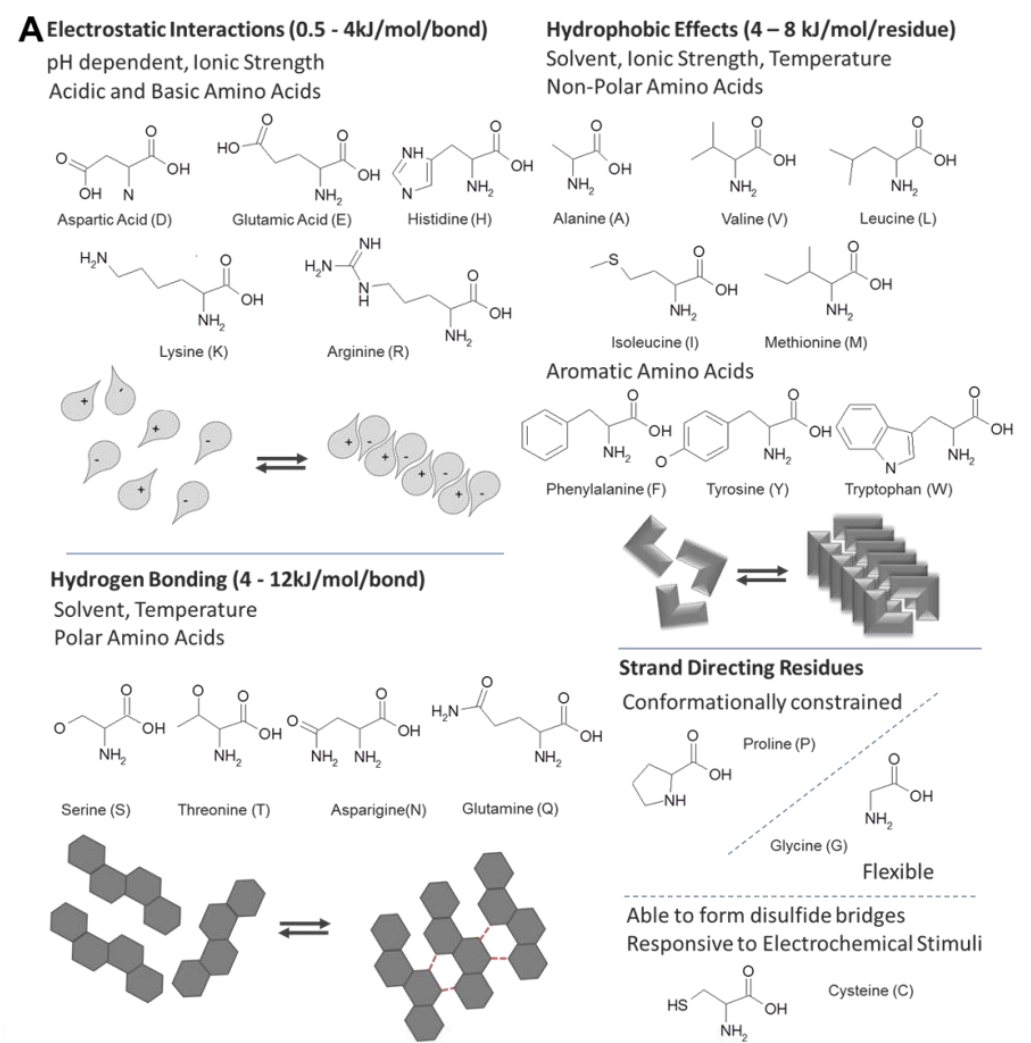

B

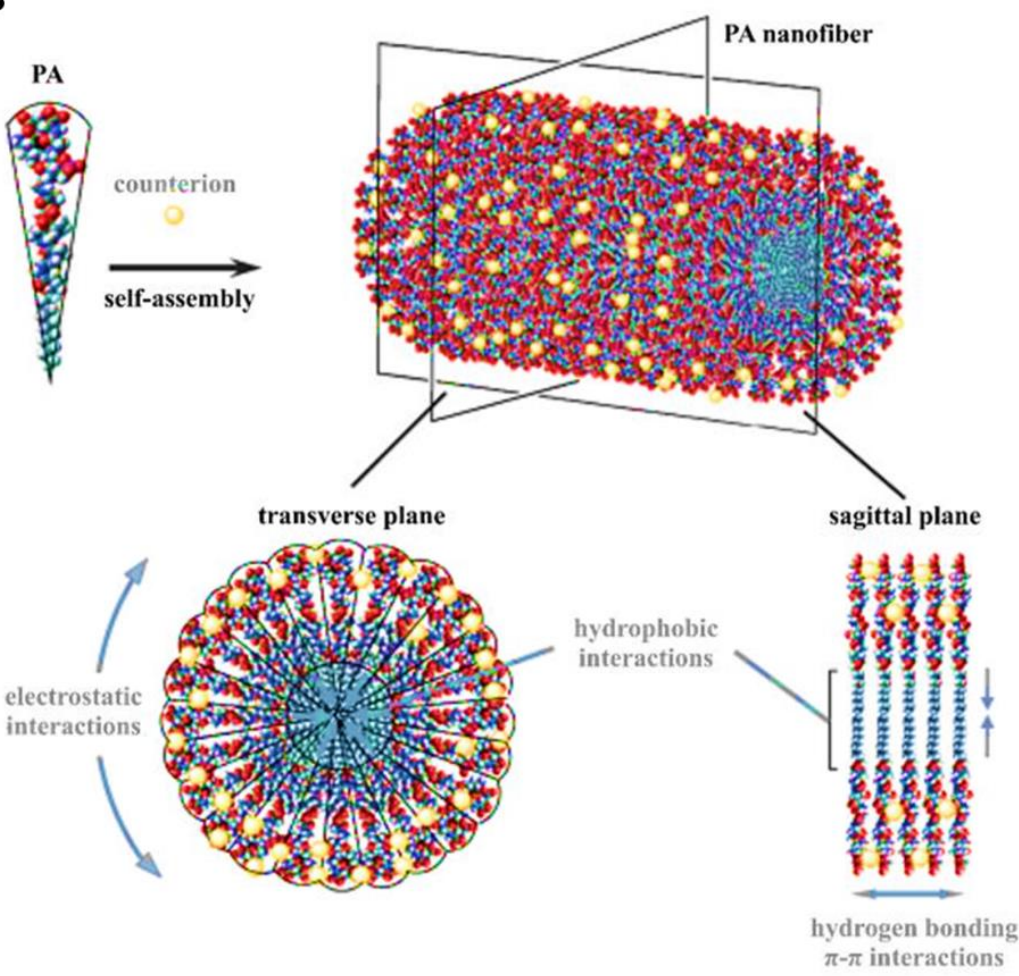

Figure $1 \mathrm{~A}$ : Different classes of amino acids and types of interactions they are involved in, B: Schematic representation of PAs self-assembly driving forces (Modified from [28, 49]). 


\subsection{Hydrogen bonding}

Peptide nanofibres are normally formed form $\beta$-sheet forming peptide chains linked to a terminal alkyl group forming a central hydrophobic core [7, 43, 50-55]. Hartgerink and coworkers., using a series of $\mathrm{K}_{n}(\mathrm{QL})_{6} \mathrm{~K}_{n}$ peptides, investigated the forces involved in the peptides self-assembly into nanofibers [51]. The hydrophobic packing of the non-polar leucine is driving the assembly, but does not control the morphology of the self-assembled peptides, which is in turn stabilised only via formation of $\beta$ sheets and hydrogen bonding directing the anisotropy of the structure [51]. Using a surfactant like peptide with a glycine spacer separating the hydrophobic from the polar charged region of the amphiphile ( $\left.\mathrm{C}_{16} \mathrm{G}_{7} \mathrm{ERGDS}\right)$, Paramonov et al. illustrated that methylations of the four glycines closest to the core of the nanofiber, in the proximity of the hydrophobic alkyl tail eliminates the ability of a PA to form elongated, cylindrical nanostructures, and thus its ability to gel [50]. However, methylation of the three glycine residues closer to the hydrophilic region resulted in the abolishment of the $\beta$-sheet and formation of polyproline type II structures. The polyproline type II (PPII) conformation forms extended form turns counterclockwise (left-handed) and contrary to the a-helix and $\beta$-sheet conformation, it is not cooperative and it is typically found in equilibrium with dihedral angles of the extended $\beta$-sheet [56]. Thus, PPII conformation are less ordered as they are not stabilised by hydrogen bonds and the PPII dihedral angles of one amino acid is energetically favoured by the equal conformation of the neighbouring amino acids [57]. However, in peptide selfassemblies, the PPII conformation remains largely unexplored. 
Dong et al. [51] illustrated the need for a balance between the hydrophilic and hydrophobic attractive forces using a model ABA tri-block peptide (Kn(QL)mKn). When $\mathrm{m} / \mathrm{n} \geq 3$, soluble peptide nanofibers with a diameter of $6 \pm 1 \mathrm{~nm}$ diameter and length $120 \pm 30 \mathrm{~nm}$ were fabricated from a decapeptide $(m+2 n=10)$ stabilised by $\beta$ sheets. Similarly, the cooperative effect of these driving forces were investigated using shorter PAs: $\mathrm{I}_{(3-5)} \mathrm{K}, \mathrm{L}_{(3-5)} \mathrm{K}$ and $\mathrm{LI}_{2} \mathrm{~K}$ [43]. Leucine residues had a weaker tendency in promoting $\beta$-sheet structures compared to isoleucine residues with the hydrophobic interactions being predominant compared to axial hydrogen bonding in isoleucine PAs. At least 4 leucine residues were necessary for $\beta$-sheet stabilised nanofibers to form, while increasing the number of isoleucine residues had no effect in the self-assembly of the PAs but only to their diameter and length [43].

\section{$4.3 \pi-\pi$ Interactions}

The critical involvement of $\pi-\pi$ interactions was illustrated by diphenylalanine dipeptides forming nanotubes via $\pi$-stacking and hydrogen bonding [16-18, 58], which is the core recognition element of the Alzheimer's a-amyloid polypeptide. Other researchers have illustrated the significance of $\pi-\pi$ stacking by studying $\mathrm{N}$-(fluorenylmethoxycarbonyl) (Fmoc) amino acids interactions and illustrated that $\pi-\pi$ interactions between the fluorenyl groups provided part of the required linkages for the gelation [59]. Studies using Fmoc-diphenylalanine illustrated that anti-parallel $\beta$ sheets can form tubular structures able to gel formed by the interlocking through $\pi-\pi$ interactions of four twisted $\beta$-sheets [60]. The contribution of aromatic amino acids as phenylalanine $(F)$, tyrosine $(Y)$ and tryptophan $(W)$ in $\pi-\pi$ interactions was assessed using $A B A$ triblock $P A s\left(K_{2}(Q F){ }_{6} K_{2}, K_{2}(Q Y)_{6} K_{2}\right.$ and $K_{2}(Q W)_{6} K_{2}$ peptides) [61]. The 
type of aromatic amino acid selected affect the length and stability of resulting nanofibers with phenylalanine producing anti-parallel $\beta$-sheets, long fibers and stable hydrogels, while tyrosine and tryptophan yielded parallel $\beta$-sheets, short fibers and hydrogels with poor properties. Despite the differences in side chain bulkiness, the intra-tape spacing between the peptides remained close to $0.48 \mathrm{~nm}$ for all multidomain peptides in both parallel and anti-parallel orientation, which allows optimal hydrogen bonding in both cases. The balance of intermolecular aromaticaromatic interactions and hydrogen bonds has been shown to be critical in preparation of biocompatible short PAs (pentapeptides) containing tyrosine and phenylalanine residues (at least 2 aromatic amino acids per peptide sequence) that can act as hydrogelators in a concentration of $0.5-2.8 \% \mathrm{w} / \mathrm{v}$ [62]. Interestingly, the introduction of a conformational constraint by disulfide-bond-mediated peptide cyclization was able to disrupt aromatic-aromatic interactions of a short PAs (Ac$\mathrm{C}(\mathrm{FKFE}) 2 \mathrm{CG})$ and enable the creation of a responsive amphiphile able to gel in reductive environments by favouring the adoption of $\beta$-sheet conformation [63].

\subsection{Electrostatic Interactions}

Electrostatic interactions between the charged amino acids of the hydrophilic head, as well as the hydrophobic tail interactions, are dominant non-selective driving forces of the PAs self-assembly (Table 1). Israelachvili has described that balance between attractive (hydrophobic) and repulsive (electrostatic) forces are critical in determining the geometry of amphiphiles with minimum free energy [24]. The critical packing parameter (CPP) characterised by the molecular area of the hydrophilic head, $a$, the molecular volume of the hydrophobic tail, $v$, and the molecular length of the hydrophobic tail, I, can be used to predict the morphology of the overall assembly: 
$C P P=\frac{\mathrm{v}}{a_{\mathrm{o}} l}$

(Equation

1) [24]. For

fibrils to result, a CPP value of between $1 / 3$ to $1 / 2$ is necessary [7].

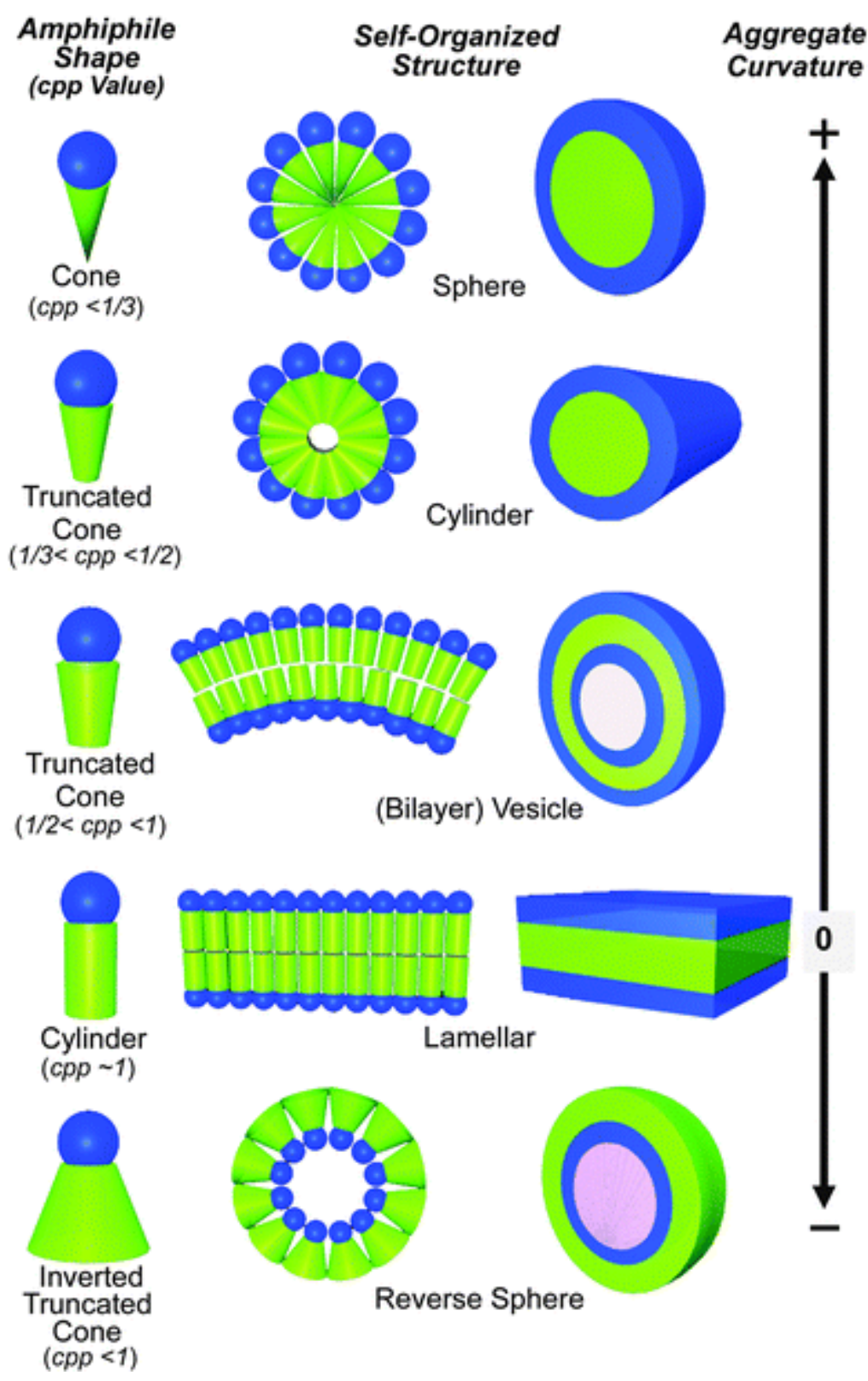

Figure 2: Molecular structure of amphiphiles, preferred aggregate structures, and the related aggregate curvature. Reproduced with permission from: [64] 
Modifications of the hydrophilic region in terms of size and charge can gravely affect the self-assembly with increase in size reducing proportionally the CPP $[65,66]$, which can result in a spherical morphology, if this reduction is adequate [51]. Enhancing the amphipathicity of PAs can result in more stable assemblies. Deamination of $\mathrm{Ac}-\mathrm{A}_{6} \mathrm{~K}-\mathrm{CONH}_{2}$ exposed the carboxyl group and yielded a negative charge to the hydrophilic region that resulted to a PA with a lower CAC and enhanced stability [65]. Alternatively, amphipathic $\mathrm{X}_{6} \mathrm{~K}_{n}$ peptides (where $\mathrm{X}$ is a hydrophobic amino acid i.e. A, V, or L) with identical hydrophobic regions, but with an increased number of hydrophilic amino acids possess an increased CAC (from micromolar to millimolar range) and formed vesicles or irregular aggregates compared to nanotubes [66].

Beyond experimental studies of the self-assembly of PAs, a number of theoretical calculations have been reported to predict the self-assembly of PAs [67-73]. Most recently, the Schatz group investigated the assembly of the SLSLAAAEIKVAV peptide using steered molecular dynamics simulations [71] and targeted molecular dynamics simulations [72]. Obtained data indicated that the driving forces for selfassembly are enthalpic with electrostatic and, mainly, van der Waals interactions playing an important role in the stabilization of the nanofibers [71]. The total electrostatic interactions contributed towards the $86 \%$ of the total driving force of which $54 \%$ were solvent electrostatic interactions while van der Waals forces contributed to $12 \%$ of the total driving force [72]. Overall the mechanistic picture for PA self-assembly is that the PAs transfer from free state to bound state occurs in two stages based on these predictions: i) PAs approach each other while aggregation, 
desolvation, and head-tail conformational reorganization occurs (this stage can be viewed as being dominated by PA movement toward the center of the micelle, while solvent moves away); ii) PAs organize together to make a conformational disorder-toorder transition, including forming more secondary structures and tail-head core-shell alignment associated with a rapidly decreasing potential of mean force (PMF) [72].. In the first stage, the PMF decreases smoothly (and slowly) as the solvent-solvent and PA-solvent interaction energies show additional structure as a function of $\mathrm{Rg}$ (radius of gyration) in which PA-solvent and solvent-solvent interactions change more rapidly at long range ( $>45 \AA$ ) than at shorter range. This long- range variation arises from desolvation of the PA head groups as the PAs come together [72].

Beside hydrophobic, hydrogen bonding, m-stacking and electrostatic interactions, Stendahl et al. described the effect of the concentration, electronic structure and hydration of the counterions on the self-assembly of a $\mathrm{C}_{16} \mathrm{~A}_{4} \mathrm{G}_{3} \mathrm{~S}(\mathrm{P}) \mathrm{KGE}-\mathrm{COOH} \mathrm{PA}$ [49]. Atomic force and transmission electron microscopy studies illustrated formation of PA gels when metal particularly divalent chelators were added (i.e. $\mathrm{Ca}^{+2}$ ) [49]. Higher valence ions, $f, p$ and d-block elements, revealed the formation of elastic gels while lower valence ions, s-block elements, gels were classified as viscous liquids [49].

\section{Applications of PAs in Drug Delivery}

The ability of the PAs molecules to organize into well-defined nanostructures, micelles, vesicles, nanospheres, nanofibers and nanotubes, is clearly relevant for 
drug delivery considering the potential of the PAs in permeating biological barriers as well as safe degradation products (Table 1).

\subsection{Clinically translated supramolecular PA assemblies}

The only licensed PA supramolecular assembly was approved by the Food and Drug Administration (FDA) based on lanreotide, a somatostatin analog. Somatostatin is a hormone regulating gastrointestinal tract modulation and proliferation of normal and tumour cells. Lanreotide (Figure 3) is licensed for the treatment of acromegaly and for the treatment of neuroendocrine tumours and is currently available as Somatuline LA $\AA$ that requires intramuscular administration once every $10-14$ days or as a subcutaneous monthly implant, Somatuline AutogelO [74]. Lanreotide has been shown to spontaneously self-assemble into monodisperse nanotubes [75]. Lanreotide (cyclic octapeptide, H-D-2-NAL-CYS-TYR-D-TRP-LYS-VAL-CYS-THR$\mathrm{NH}_{2}$ ) is able to self-assemble in aqueous environments at concentration of $3-18 \%$ $\mathrm{w} / \mathrm{w}$ by forming hollow nanotubes with a $24.4 \mathrm{~nm}$ diameter and lengths up to hundreds of micrometers [75-80]. Each nanotube wall consists of 26 helicoidal filaments that are formed by peptides self-assembled into anti-parallel $\beta$-sheets through an alternating pattern of the aliphatic and aromatic amino acids [75]. The effect of the peptide concentration, 2 to $70 \%(\mathrm{w} / \mathrm{w})$, and temperature, 15 to $70{ }^{\circ} \mathrm{C}$, was studied by Valéry et al. [76]. The results revealed the hexagonal packing of nanotubes, and high degree of monodispersity in the tube diameter (244 $\AA$ ) and wall thickness ( 18 $\AA$ ) [75]. Using Raman and fluorescence spectroscopy, it was shown that the molecular and supramolecular packing of lanreotide is stabilized by 1) naphthalene side chains involved in specific molecular interactions/orientations, 2) tyrosines that stabilize the filaments and the double-walled layer of filaments and 3) 
W-W aromatic packing, in which the tryptophans residues are oriented inward or outward from the nanotube layers towards the water modulating the tube curvature [77]. The modification of the conformation by opening the cycle, replacing the lysine or the aromatic amino acids with alanine, with the latter abolishing nanotube formation, illustrating the importance of the aromatic residues in the lanreotide selfassembly [78].

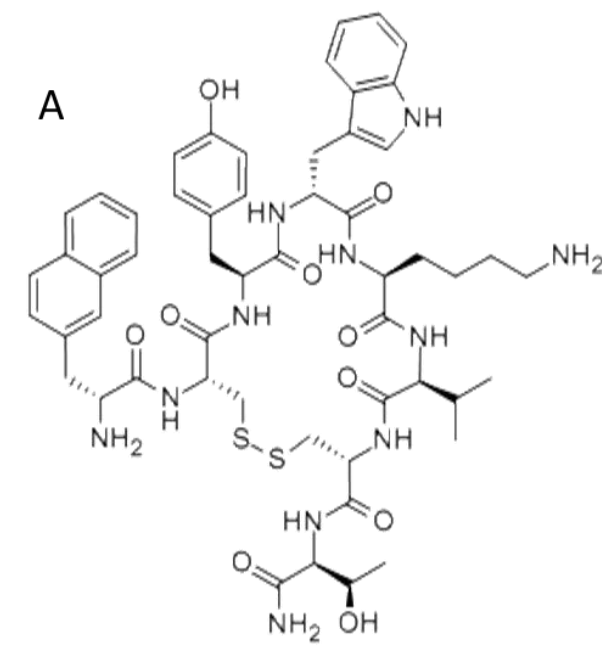

B

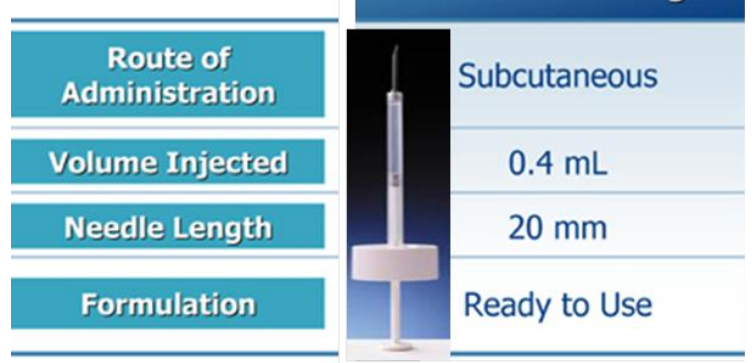

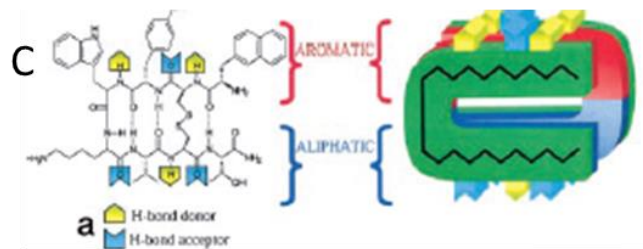
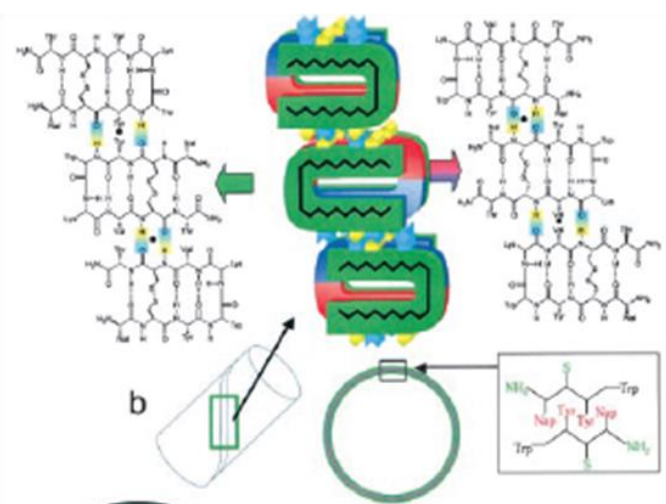

C

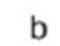

b
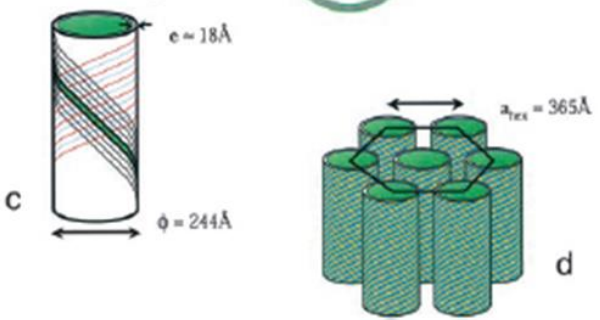

Figure 3: A: Lanreotide chemical structure, B: Somatuline Autogel $\AA$ final dosage form and administration details, C: Schematic view of the different hierarchical levels in the self-assembly of the lanreotide-acetate nanotubes in water; a) Lanreotide molecule in the hairpin planar conformation is stabilised by the disulphide bridge, the turn and the intramolecular hydrogen bonds, b) The structure of a filament with two different $\beta$-sheet fibers superimposed with their $\mathrm{C} 22$-fold axes (black circles) meeting together , c) Self-assembly of 26-sheets fibers to form a nanotube, d) Liquid crystalline hexagonal columnar phase formed by the nanotubes. Modified with permission from: [75] 
Table 2 Summary of studies of PAs developed for drug delivery applications.

\begin{tabular}{|c|c|c|c|c|c|c|c|}
\hline Phase & PA & Drug & Nanostructure & Route & Application & Outcome & Ref. \\
\hline Clinical & $\begin{array}{c}\text { Lanreotide } \\
\mathrm{NH}_{2-} \text { (D)Naph-CY(D)WKVCT- } \\
\mathrm{CONH}_{2}\end{array}$ & - & Nanotubes & $\begin{array}{l}\mathrm{IM} \\
\mathrm{SC}\end{array}$ & $\begin{array}{l}\text { Acromegaly and TSH- } \\
\text { secreting pituitary } \\
\text { adenomas }\end{array}$ & $\begin{array}{l}\text { Significant reduction in the tumour } \\
\text { size. Reduction or normalisation } \\
\text { of circulating GH ( } 57 \% \text { of } \\
\text { patients) and IGF-1 levels }(67 \% \\
\text { of patients) (meta-analysis of } 44 \\
\text { studies) } \\
\end{array}$ & $\begin{array}{l}{[74,} \\
75, \\
81]\end{array}$ \\
\hline \multirow{8}{*}{$\begin{array}{l}\text { Preclinical } \\
\text { In vivo }\end{array}$} & $\begin{array}{l}\text { Leucine-Enkephalin } \\
\mathrm{NH}_{2}-\mathrm{Y}(-\mathrm{O}-\text {-palmitoyl)GGFL-OH }\end{array}$ & $\begin{array}{l}\text { Leucine- } \\
\text { Enkephalin }\end{array}$ & $\begin{array}{l}\text { Quaternary } \\
\text { ammonium } \\
\text { palmitoyl chitosan } \\
\text { coated nanofibers }\end{array}$ & $\begin{array}{l}\text { IV } \\
\text { Oral }\end{array}$ & Pain & $\begin{array}{l}\text { Antinociception lasting } 2-8 \mathrm{~h} \\
\text { after oral administration. } \\
\text { Increased brain uptake after oral } \\
(67 \%) \text { and IV administration } \\
(50 \%) \text {. }\end{array}$ & $\begin{array}{r}111, \\
15]\end{array}$ \\
\hline & $\mathrm{NH}_{2}-\mathrm{Y}(-\mathrm{O}$-palmitoyl)GGFLR-OH & Dalargin & $\begin{array}{l}\text { Quaternary } \\
\text { ammonium } \\
\text { palmitoyl chitosan } \\
\text { coated nanofibers }\end{array}$ & IV & Pain & $\begin{array}{l}\text { Significant antinociception } \\
\text { between } 1-3 \text { hrs post IV dosing }\end{array}$ & [25] \\
\hline & $\begin{array}{c}\text { RAD16-II } \\
\text { AcN-(RARADADA) } 2-\mathrm{CNH}_{2}\end{array}$ & IGF-1 & Nanofibers & $\begin{array}{l}\text { Local } \\
\text { injection }\end{array}$ & Myocardial infarction & $\begin{array}{l}\text { Specific and prolonged delivery of } \\
\text { IGF-1 increasing cardiomyocyte } \\
\text { growth in vitro and in vivo }\end{array}$ & [82] \\
\hline & Palmitoyl-G $\mathrm{G}_{3} \mathrm{~A}_{4} \mathrm{IKVAV}$ & - & Nanofibers & $\begin{array}{l}\text { Local } \\
\text { injection }\end{array}$ & Spinal cord injury & $\begin{array}{l}\text { Reduced astrogliosis and cell } \\
\text { death and regeneration of motor } \\
\text { and sensory neurons }\end{array}$ & [39] \\
\hline & Palmitoyl- $\mathrm{V}_{2} \mathrm{~A}_{2} \mathrm{E}_{2}-\mathrm{NH}_{2}$ & $\mathrm{SHH}$ & Nanofibers & $\begin{array}{l}\text { Local } \\
\text { injection }\end{array}$ & Cavernous nerve injury & $\begin{array}{c}\text { Regeneration of the nerve, } \\
\text { suppression of penile apoptosis } \\
\text { and } 58 \% \text { of improvement of } \\
\text { erectile function }\end{array}$ & [83] \\
\hline & Palmitoyl- $\mathrm{V}_{2} \mathrm{~A}_{2} \mathrm{E}_{2} \mathrm{~K}$ & $\begin{array}{l}\text { Dexametha- } \\
\text { sone }\end{array}$ & Nanofibers & SC & inflammation & $\begin{array}{l}\text { Significant reduction in } \\
\text { inflammation with a low number of } \\
\text { infiltrating inflammatory cells }\end{array}$ & [84] \\
\hline & Palmitoyl- $\mathrm{A}_{4} \mathrm{G}_{3} \mathrm{E}_{3}$ & Camptothe-cin & Nanofibers & IV & Cancer & $\begin{array}{l}2.5 \text {-fold decrease of breast } \\
\text { cancer xenograft growth }\end{array}$ & [85] \\
\hline & $\begin{array}{c}\text { Palmitoyl-(K)- } \\
\mathrm{V}_{3} \mathrm{E}_{3} \text { SGGGYPVHPST-NH }\end{array}$ & BMP-2 & Nanofibers & $\begin{array}{l}\text { Local } \\
\text { implantation }\end{array}$ & Spinal arthrodesis & $\begin{array}{c}10 \text {-fold reduction in dose } \\
\text { necessary to achieve } 100 \% \\
\text { fusion rate and } 42 \% \text { fusion rate } \\
\text { without exogenous BMP-2 }\end{array}$ & [86] \\
\hline
\end{tabular}




\begin{tabular}{|c|c|c|c|c|c|c|c|}
\hline \multirow{9}{*}{ In vitro } & $\begin{array}{c}\text { Chol/Palmitoyl- } \mathrm{A}_{4} \mathrm{G}_{3} \mathrm{KRGDS} \\
\text { Chol/Palmitoyl- } \\
\mathrm{A}_{4} \mathrm{G}_{2} \mathrm{EGRGDS}\end{array}$ & $\begin{array}{c}\text { Pyrene } \\
\text { (as a model } \\
\text { drug) }\end{array}$ & Nanofibers & - & $\begin{array}{l}\text { Delivery of } \\
\text { hydrophobic drugs to } \\
\text { tumours }\end{array}$ & $\begin{array}{l}\text { Efficient encapsulation of } \\
\text { pyrene in the nanofiber } \\
\text { hydrophobic core }\end{array}$ & [87] \\
\hline & $\begin{array}{l}\text { Dipalmitoyl - } \\
(\text { LRKLRKRLLR })_{2}\end{array}$ & 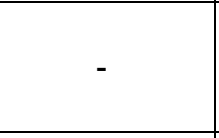 & Micelles & - & $\begin{array}{l}\text { Intracellular delivery } \\
\text { of hydrophobic drugs }\end{array}$ & $\begin{array}{l}\text { Efficient internalization of } \\
\text { micelles into mouse brain } \\
\text { capillary endothelial cells }\end{array}$ & [88] \\
\hline & Dioctadecyl-L5CCK8 & $\begin{array}{c}\text { Pyrene } \\
\text { Doxorubicin }\end{array}$ & Micelles & - & $\begin{array}{c}\text { Delivery of } \\
\text { hydrophobic drugs }\end{array}$ & $\begin{array}{c}\text { Fluorescence experiments } \\
\text { indicated the entrapment of } \\
\text { pyrene/doxorubicin within the } \\
\text { PAs }\end{array}$ & [89] \\
\hline & Ac-AAVVLLLWE $2 / 7-\mathrm{COOH}$ & $\begin{array}{c}\text { Calcein } \\
\text { (as a model) }\end{array}$ & Vesicles & - & $\begin{array}{c}\text { Delivery of } \\
\text { hydrophilic drugs }\end{array}$ & $\begin{array}{c}\text { Formation of } \mathrm{pH} \text {-sensitive } \\
\text { vesicles loaded with a water } \\
\text { soluble molecule }\end{array}$ & [90] \\
\hline & $\begin{array}{c}\text { Palmitoyl- } \\
\text { GTAGLIGQRGDS-COOH }\end{array}$ & Cisplatin & Nanofibers & - & $\begin{array}{l}\text { Ovarian, testicular } \\
\text { and bladder cancer, } \\
\text { lymphoma and } \\
\text { glioma }\end{array}$ & $\begin{array}{l}\text { Loading efficiencies of } 98.7 \% \text {. } \\
\text { Drug release triggered by the } \\
\text { cleavage of MMP-2-sensitive } \\
\text { sequence in the peptide }\end{array}$ & [91] \\
\hline & $(\mathrm{AF})_{6} \mathrm{H}_{5} \mathrm{~K}_{15}$ & $\begin{array}{l}\text { Doxorubicin } \\
\text { and p53 } \\
\text { gene }\end{array}$ & Micelles & - & Hepatocarcinoma & $\begin{array}{l}\text { Drug loading of } 22 \% \text {. } \\
\text { Simultaneous intracellular } \\
\text { delivery of the drug and the } \\
\text { gene into HepG2 cells }\end{array}$ & [92] \\
\hline & Palmitoyl- $A_{4} \mathrm{G}_{3} \mathrm{LRK} \mathrm{K}_{2} \mathrm{LGKA}$ & $\begin{array}{l}\text { VEGF and } \\
\text { FGF-2 }\end{array}$ & Nanofibers & - & Type 1 Diabetes & $\begin{array}{l}\text { Improvement of transplanted } \\
\text { pancreatic islets survival and } \\
4.5 \text {-fold increase of cell } \\
\text { sprouting. Increased glucose } \\
\text { secretion } \\
\end{array}$ & [93] \\
\hline & Palmitoyl- $\mathrm{A}_{4} \mathrm{G}_{3}(\mathrm{KLAKLAK})_{2}$ & - & Nanofibers & - & Cancer & $\begin{array}{c}\text { Death of breast cancer cells } \\
\text { induced by caspase- } \\
\text { independent and Bax/Bak- } \\
\text { independent mechanisms } \\
\text { associated with membrane } \\
\text { lysis }\end{array}$ & [94] \\
\hline & $\begin{array}{l}\text { Palmitoyl-(ADA) })_{2}-R G D \\
\text { Octadecyl-(ADA)2-RGD }\end{array}$ & Paclitaxel & Micelles & - & $\begin{array}{l}\text { Ovarian, breast, lung } \\
\text { cancer, acute } \\
\text { leukemia and others. }\end{array}$ & $\begin{array}{c}\text { Palmitoyl-(ADA)2-RGD } \\
\text { micelles exhibited lowest } \\
\text { CMC, } 9 \pm 1.73 \mu \mathrm{M} \text {, and cellular } \\
\text { uptake by A2058 melanoma } \\
\text { cells }\end{array}$ & [95] \\
\hline
\end{tabular}




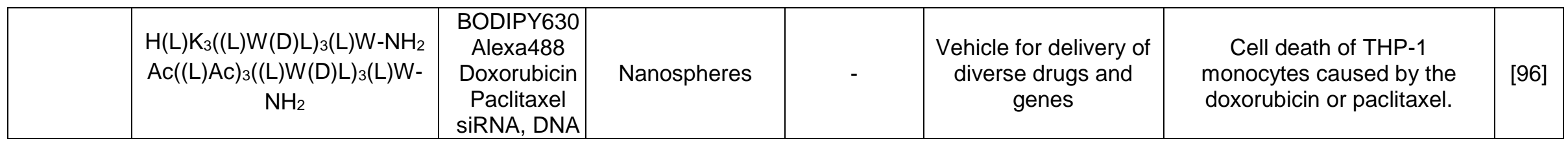

Key: BMP-2 (bone morphogenetic protein-2), Chol (cholesterol), CMC (critical micelle concentration), FGF-2 (fibroblast growth factor-2), IGF-1 (insulinlike growth factor-1), IM (intramuscular), IV (intravenous), MMP-2 (matrix metalloproteinase-2), NPs (nanoparticles), PEG (poly(ethylene glycol), SC (subcutaneous), SHH (sonic hedgehog), TSH (thyroid-stimulating hormone), VEGF (vascular endothelial growth factor); FGF-2 (fibroblast growth factor2). 


\subsection{Preclinical studies}

Only peptide nanofibers are at the moment undergoing preclinical research mainly in the area of delivery across the blood-brain barrier, the oral mucosa, regenerative medicine, inflammation and cancer (Table 2) with majority of PAs containing a palmitoyl single tail. Peptide nanofibers have shown promise in delivering peptides across challenging barriers such as the oral mucosa and the blood-brain barrier [2]. Due to their amphipathic structure they are able to permeate better across biological barriers, while self-assembled peptide show superior enzymatic stability to digestive enzymes as well as plasma, brain and liver enzymes [15]. Pharmacokinetic studies of two PAs of leucine-encephalin (an endogenous opioid neuropeptide) synthetic analogues [NH2-Y(-O-palmitoyl) GGFL-OH (TPLENK) and NH2-Y(-O-palmitoyl)GGFLR-OH) TP-Dalargin] illustrated that nanofibers permeate across the blood-brain barrier in significant amounts and able to achieve central antinociception after intravenous [11, 25] and oral administration [15], and there are they only studies reporting pharmacokinetic parameters for PAs self-assemblies. Nanofibers consisted of central hydrophobic core surrounded by a $\beta$-sheet of peptides. As the alkyl chains associate, this $\beta$-sheet formation confounds the self-assembly and prevents the assembling molecules from achieving a marked radius of curvature and spherical shape, instead giving rise to a hydrophobic cylindrical assembly surrounded by a $\beta$-sheet, with the cylindrical assembly primarily driven by the $\beta$ sheet formation. The presence of charges amino acid such as the positively charged arginine residue [5] in TP-Dalargin is not critical for self-assembly as TPLENK is able to self-assemble due to aromatic stacking and solvophobic and hydrophobic interactions [7, 11]. Quaternary ammonium glycol chitosan 
polymers were used to coat the resulting nanofibers which resulted in reduction of protein binding and liver uptake of nanofibers and aided in enhancing the brain bioavailability of the nanofibers after intravenous administration [11] and enabled the oral uptake of peptide nanofibers across the oral mucosa [15].
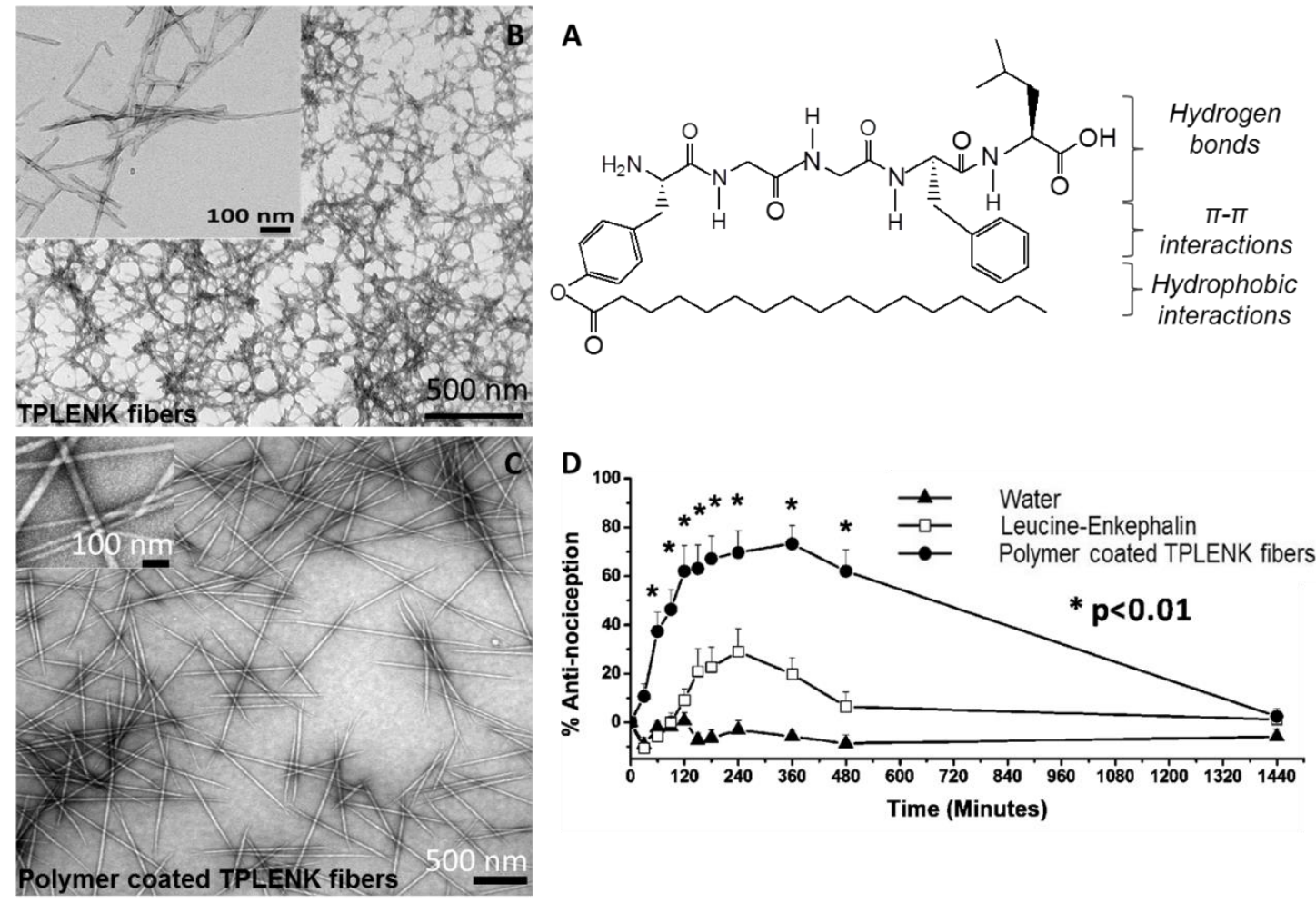

Figure 4: A: Acylated Leucine Enkephalin (TPLENK) PA structure and schematic view of the different regions of the PAs and forces driving its selfassembly in nanofibers in water, B and C: Transmission electron microscopy images of TPLENK nanofibers $(4 \% \mathrm{w} / \mathrm{v}$ in $2.25 \%$ glycerol) and quaternary ammonium glycol chitosan (GCPQ 10kDa) polymer overcoated TPLENK nanofibers $(4 \% \mathrm{w} / \mathrm{v}$ in $0.9 \%$ sodium chloride, PA : polymer ratio: $1: 5 \mathrm{w} / \mathrm{w}), \mathrm{D}$ : Tail-flick bioassay \% antinociception (mean \pm SEM, $n=16$ ) recorded for orally dosed mice with water $(\boldsymbol{\Lambda})$, leucine-enkephalin $\left(70 \mathrm{mg} \mathrm{kg}^{-1}, \square\right)$, TPLENK (100 $\left.\mathrm{mg} \mathrm{kg}^{-1}\right)$ - GCPQ $\left(14 \mathrm{kDa}, 500 \mathrm{mg} \mathrm{kg}^{-1}\right)(\bullet)$. Modified from [11].

Peptide amphiphiles are under intense research in the field of regenerative medicine and tissue regeneration [39, 82, 83]. An example of this is a "biotin sandwich" approach was described for the controlled delivery of insulin-like growth factor (IGF-1) to local myocardial infarction environments for cardiac repair [82]. Biotinylated IGF-1 was complexed with tetravalent streptavidin and 
then bound to biotinylated self-assembling peptides RAD16 II (AcN(RARADADA)2- $\mathrm{CNH}_{2}$ ) peptides. These fused growth factor with self-assembling peptides resulted in a five-fold increase of the IGF-1 binding comparing to the non-biotinylated peptides [82], while the peptides with tethered IGF-1 promoted the long-term activation of survival pathways and increase the expression of the cardiac maturation markers. Adult sprague Dawley rats suffering from a myocardial infarction, were immediately exposed to cardiomyocytes alone of embedded within the self-assembling peptides $(80 \mu \mathrm{L})$ into the infarct zone via a 30-gauze needle. After 21 days, the tethered IGF-1 promoted a significant reduction of the implanted myocytes apoptosis compared to the RAD16Il alone or untethered IGF-1 [82]. Over the last years, the Stupp group has reported on the potential of PAs for the regeneration of spinal cord and cavernous nervous injuries $[39,83,97]$. PA (palmitoyl-G $\mathrm{A}_{4} \mid \mathrm{KVAV}$ ) incorporating the neuroactive epitope from laminin (IKVAV) promoted the outgrowth of processes from in vitro cultured neurons and suppress the astrocytic differentiation of neural progenitor cells [38]. Local injection of palmitoyl-G $\mathrm{G}_{4}$ IKVAV in a mouse spinal cord injury model resulted in 1.5-fold decrease of glial fibrillary acid protein (GFAP) immunofluorescence, cell death reduction and increase of the oligodendroglia at the lesion site [39]. The IKVAV PA promoted also the regeneration of the descending motor and ascending sensory neurons [39].

PAs have also shown potential in peripheral nervous system regeneration especially of the cavernous nerve [83]. Peripheral nerve injury of the cavernous nerve $(\mathrm{CN})$ is a significant concern to diabetic, aging, metabolic syndrome and prostate cancer patients who develop erectile dysfunction (ED) as a result of 
denervation of the penis [83]. The sonic hedgehog $(\mathrm{SHH})$ protein has been shown to have beneficial effects in cavernous nerve injury and regeneration [98, 99] and therefore, in preventing penile apoptosis and erectile dysfunction. Thus, delivery of SHH entrapped by palmitoyl- $\mathrm{V}_{2} \mathrm{~A}_{2} \mathrm{E}_{2}-\mathrm{NH}_{2}$ nanofibers to the cavernous nerve after local injection suppressed the penile apoptosis and caused a $58 \%$ improvement in erectile functional in less than half of the time reported in the literature [83].

Modular PAs assembled in nanofibers (palmitoyl- $\mathrm{V}_{2} \mathrm{~A}_{2} \mathrm{E}_{2} \mathrm{~K}$ ) have also shown beneficial effects in immunosuppression to improve cell or tissue transplantation [84]. Conjugation of an anti-inflammatory drug, dexamethasone via a hydrolytically labile hydrazine bond to peptide nanofibers enabled a faster release of the steroid at weekly acidic $\mathrm{pH}(\mathrm{pH} \mathrm{5-6)} \mathrm{compared} \mathrm{to} \mathrm{physiological}$ (pH 7.4) [100]. Cumulative release studies of dexamethasone-conjugated nanofibers displayed minimal burst release and zero-order release kinetics with sustained release over 32-day study. At the end of the study, only $40 \%$ of the total amount of drug was released from the nanofibers gel. Free dexamethasone mixed with the peptide revealed a greater burst release at the initial time points and then, a faster release profile with all the drug released in 32 days [84]. Histological studies in mice illustrated a marked reduction in the number of infiltrating inflammatory cells when cell-surrogate polystyrene microparticles impanted in mice were delivered within Dex-PA nanofiber gels, and very little inflammation was observed at either 3 days or 21 days postimplantation [84]. 
PAs nanofibers also finally have illustrated potential in the treatment of breast cancer by exploiting EPR effect. High encapsulation of camptothecin (a naturally occurring quinoline alkaloid) into palmitoyl- $A_{4} G_{3} E_{3}$ peptide nanofibers was achieved (loading efficiencies of $72 \%$ ) and enabled a 50 -fold enhancement in camptothecin aqueous solubility [85]. Small-angle X-ray scattering results suggested a slight increase in diameter of the nanofiber to accommodate the hydrophobic cargo and treatment with camptothecin loaded nanofibers resulted in a 2.5 fold decrease in breast cancer xenograft murine model [85].

PA nanofibers (Palmitoyl-(K)-V3E3SGGGYPVHPST-NH 2 ) with binding affinity for the bone promoting growth factor BMP-2 have been reported to create a gel scaffold for osteogenesis [86]. The efficacy of the bioactive PA system to promote BMP-2-induced osteogenesis in vivo was investigated in a rat posterolateral lumbar intertransverse spinal fusion model. PA nanofiber gels displaying BMP-2-binding segments exhibit superior spinal fusion rates relative to controls, effectively decreasing the required therapeutic dose of BMP-2 by 10 -fold [86]. A $42 \%$ fusion rate was also observed for gels containing the bioactive nanofibers without the use of exogenous BMP-2, suggesting the ability of the PA nanofibers to recruit endogenous growth factors [86].

\subsection{In vitro Studies}

A greater variety of PAs are explored in in vitro studies for cancer therapy [91, 92, 94, 95], type 1 diabetes [93] and as models for the delivery of hydrophobic [87-89] and hydrophilic drugs [90]. A modular PA created between the attachment of a palmitoyl tail to a cell adhesive matrix metalloproteinase-2 (MMP-2) sensitive peptide (GTAGLIGQRGDS) has shown potential in vitro for 
the targeted treatment of testicular, ovarian and bladder cancer as well as lymphoma and glioma [47, 91, 101] (types of cancers known to overexpress high levels of MMP-2 which playing a critical role in tumour progression, angiogenesis and metastasis [1, 102]. RGDS peptide is a tetrapeptide found on fibronectin, fibrinogen $\alpha$, and von Willebrand factor able to interact with $\alpha_{5} \beta_{1}$ and $\alpha_{v} \beta_{3}$ integrins. Release studies showed that MMP-2-triggered cisplatin release from the nanofibers occurred in a spatially and temporally controlled drug release via RGDS-mediated cellular interaction and MMP-2 specific biodegradation, which suggests a possible use of palmitoyl-GTAGLIGQRGDS peptides to control the in vivo delivery of anticancer drugs after implantation at the tumour site. Similarly, another targeted PA to $\alpha_{v} \beta_{3}$ integrins [103] was developed but in this case with a spherical morphology [95] for targeting of glioblastoma, melanoma, breast, prostate, ovarian and pancreatic tumours. Palmitoyl and octadecyl-(ADA)2-RGD micelles with a were loaded with a micromolar CMC $(9.00 \pm 1.73 \mu \mathrm{M})$, nanoparticulate size $(194.63 \pm 44.86 \mathrm{~nm})$ and almost neutral zeta potential $(0.27 \pm 1.96 \mathrm{mV})$ were loaded with paclitaxel and tested in A2058 melanoma cells. In vitro studies illustrated that the PA micelles were uptaken by $\alpha_{v} \beta_{3}$ expressed on A2058 melanoma cells via an energy temperature dependent mechanism and induced significant toxicity [95]. The $\mathrm{IC}_{50}$ of paclitaxel loaded in micelles decreased $50 \%$ in $\alpha \mathrm{v} \beta 3$ integrin overexpressing cells and showed a 4 fold increase in normal cells when compared to free paclitaxel [95]. PAs have been also been shown to be able to deliver apart from anticancer drugs also biomacromolecules such as genes [92, 104]. The $(A F){ }_{6} \mathrm{H}_{5} \mathrm{~K}_{15}$ peptide self-assembles into cationic micelles $(102 \pm 19 \mathrm{~nm}$, zeta potential of $22.8 \pm 0.2 \mathrm{mV}$ ) with a low CMC value of approximately 0.042 
$\mathrm{mg} / \mathrm{mL}$ able to be loaded with doxorubicin and p53 gene [92], that were internalized by HepG2 human liver carcinoma cell line (Doxorubicin loaded micelles $\mathrm{IC}_{50}$ of $1.8 \mathrm{mg} / \mathrm{L}$ ) and were able to induce significant gene expression levels. Additionally, toward novel anticancer delivery systems, Standley et al. tested a cationic palmitoyl- $\mathrm{A}_{4} \mathrm{G}_{3}(\mathrm{KLAKLAK})_{2}$ PA for breast cancer [94]. Incorporating the (KLAKLAK)2 into nanofibers stabilized the peptides a-helical conformation and enable its permeability across cells inducing a caspaseindependent and Bax/Bak-independent cell death in MDA-MB-23 and SKBR-3 breast cancer cells by lysing plasma membranes [94].

PAs have also been assessed for their potential in type 1 diabetes for enabling pancreatic islet transplantation [93]. The latter although a promising treatment for diabetic patients remains challenging due to the lack of available donors, inefficient engraftment of transplanted cells and limited durability of long-term islet function. Palmitoyl- $A_{4} G_{3} L R K_{2} L G K A$ nanofibers were recently described to enhance the survival of the islets upon transplantation through the delivery of angiogenic factors such as vascular endothelial growth factor (VEGF) and fibroblast growth factor (FGF-2) [93]. Nanofibers conjugation with growth factors resulted in a 2 -fold increase of cell viability and glucose stimulation index of murine pancreatic islets [93].

Finally, there are a number of papers reporting PAs loaded with model dyes such as pyrene or calcein as models for hydrophilic and hydrophobic drugs [8789, 93]. Pyrene, whose emission characteristics are often used to characterise the CMC of PAs [105], is commonly used as a hydrophobic drug model [87-89]. 
PAs assembled into nanospheres were also lately shown to be able to be loaded with a range of hydrophobic (BODIPY630, doxorubicin and paclitaxel), hydrophilic (Alexa 488) drugs and genes [106].

\subsection{Conclusions}

PAs, a class of peptides composed of a hydrophobic tail coupled to a hydrophilic headgroup via a spacer stabilised usually but not necessarily by $\beta$ sheets show great potential as passively or active targeted delivery systems for both hydrophobic or hydrophilic drugs and biomacromolecules. Similar to other nanomedicines, the therapeutic cargo can be encapsulated or conjugated to the range of available functional groups via an amide, ester or disulphide bond. By achieving a balance between the hydrogen, electrostatic, hydrophobic and $\pi-\pi$ interactions, the supramolecular morphology and properties of the PAs including their pharmacokinetic properties can be tailored. Majority of the PAs undergoing preclinical testing involve the addition of a single palmitic acid tail and assemble supramolecularly as nanofibers. PAs have shown promise in permeation across challenging biological barriers such as the blood-brain barrier, tissue engineering and in intercellular and targeted delivery for drugs and genes. Due to their size and high axial morphology and propensity to elicit hydrogels, subcutaneously delivery remains the first choice. However, if the morphology and pharmacokinetic characteristics are tailored, non-parenteral (intravenous, oral or nasal) delivery routes are a possibility.

\section{Conflict of Interest}

The authors declare no competing financial interest. 


\section{Acknowledgments}

The authors would like to acknowledge the support of the Institute for

Biomedical and Biomolecular Sciences, University of Portsmouth.

\section{References:}

1. Vlieghe, P., et al., Synthetic therapeutic peptides: science and market. Drug Discov Today, 2010. 15(1-2): p. 40-56.

2. Lalatsa, A., A.G. Schatzlein, and I.F. Uchegbu, Strategies to deliver peptide drugs to the brain. Mol Pharm, 2014. 11(4): p. 1081-93.

3. Lax, R.T., The future of peptide development in the pharmaceutical industry. Pharmanufacturing: The International Peptide Review, World Business Journals, Pharmaceutical Division, London, 2010.

4. Serrano Lopez, D.R. and A. Lalatsa, Peptide pills for brain diseases? Reality and future perspectives. Ther Deliv, 2013. 4(4): p. 479-501.

5. Cui, H., M.J. Webber, and S.I. Stupp, Self-assembly of peptide amphiphiles: from molecules to nanostructures to biomaterials. Biopolymers, 2010. 94(1): p. 1-18.

6. Lin, B.F., et al., De novo design of bioactive protein-resembling nanospheres via dendrimer-templated peptide amphiphile assembly. Nano Lett, 2011. 11(9): p. 394650.

7. Lalatsa, A., et al., Amphiphilic poly(L-amino acids) - new materials for drug delivery. Journal of Controlled Release, 2012. 161(2): p. 523-36.

8. Ulijn, R.V. and A.M. Smith, Designing peptide based nanomaterials Chemical Society Reviews, 2008. 37: p. 664-675.

9. Black, K.A., et al., Biocompatibility and characterization of a Peptide amphiphile hydrogel for applications in peripheral nerve regeneration. Tissue Eng Part A, 2015. 21(7-8): p. 1333-42.

10. Braun, G.B., et al., Laser-Activated Gene Silencing via Gold Nanoshell-siRNA Conjugates. ACS Nano, 2009. 3(7): p. 2007-15.

11. Lalatsa, A., et al., Chitosan amphiphile coating of peptide nanofibres reduces liver uptake and delivers the peptide to the brain on intravenous administration. J Control Release, 2015. 197: p. 87-96.

12. Zhao, X., et al., Molecular self-assembly and applications of designer peptide amphiphiles. Chemical Society Reviews, 2010. 39: p. 3480-3498.

13. Li, S.C. and C.M. Deber, Glycine and beta-branched residues support and modulate peptide helicity in membrane environments. FEBS Lett, 1992. 311(3): p. 217-20.

14. Li, S.C. and C.M. Deber, Influence of glycine residues on peptide conformation in membrane environments. Int J Pept Protein Res, 1992. 40(3-4): p. 243-8.

15. Lalatsa, A., et al., A prodrug nanoparticle approach for the oral delivery of a hydrophilic peptide, leucine(5)-enkephalin, to the brain. Molecular Pharmaceutics, 2012. 9(6): p. 1665-80.

16. Kol, N., et al., Self-assembled peptide nanotubes are uniquely rigid bioinspired supramolecular structures. Nano Lett, 2005. 5(7): p. 1343-6.

17. Yemini, M., et al., Novel electrochemical biosensing platform using self-assembled peptide nanotubes. Nano Lett, 2005. 5(1): p. 183-6. 
18. Reches, M. and E. Gazit, Designed aromatic homo-dipeptides: formation of ordered nanostructures and potential nanotechnological applications. Phys Biol, 2006. 3(1): p. S10-9.

19. Hartgerink, J.D., E. Beniash, and S.I. Stupp, Self-assembly and mineralization of peptideamphiphile nanofibers. Science, 2001. 294(5547): p. 1684-8.

20. Lowik, D.W. and J.C. van Hest, Peptide based amphiphiles. Chemical Society Reviews, 2004. 33(4): p. 234-45.

21. Kokkoli, E., et al., Self-assembly and applications of biomimetic and bioactive peptideamphiphiles. Soft Matter, 2006. 2(12): p. 1015.

22. Chung, E.J., et al., Fibrin-binding, peptide amphiphile micelles for targeting glioblastoma. Biomaterials, 2014. 35(4): p. 1249-56.

23. Tan, A., J. Rajadas, and A.M. Seifalian, Biochemical engineering nerve conduits using peptide amphiphiles. J Control Release, 2012. 163(3): p. 342-52.

24. Israelachvili, J.N., Intermolecular and Surface Forces. Third ed. 2011: Academic Press.

25. Mazza, M., et al., Nanofiber-based delivery of therapeutic peptides to the brain. ACS Nano, 2013. 7(2): p. 1016-1026.

26. van Hell, A.J., et al., Self-assembly of recombinant amphiphilic oligopeptides into vesicles. Biomacromolecules, 2007. 8(9): p. 2753-61.

27. Nagai, A., et al., Dynamic behaviors of lipid-like self-assembling peptide A6D and A6K nanotubes. J Nanosci Nanotechnol, 2007. 7(7): p. 2246-52.

28. Mart, R.J., et al., Peptide-based stimuli-responsive biomaterials. Soft Matter, 2006. 2: p. 822-35.

29. Stevens, M.M., et al., $\mathrm{pH}$-dependent behavior of surface-immobilized artificial leucine zipper proteins. Langmuir, 2004. 20(18): p. 7747-52.

30. Ciani, B., et al., A designed system for assessing how sequence affects alpha to beta conformational transitions in proteins. J Biol Chem, 2002. 277(12): p. 10150-5.

31. Pandya, M.J., et al., Sticky-end assembly of a designed peptide fiber provides insight into protein fibrillogenesis. Biochemistry, 2000. 39(30): p. 8728-34.

32. Ryadnov, M.G., D. Papapostolou, and D.N. Woolfson, The leucine zipper as a building block for self-assembled protein fibers. Methods Mol Biol, 2008. 474: p. 35-51.

33. Rawsterne, R.E., et al., Controlling protein retention on enzyme-responsive surfaces. Surf Interface Anal, 2006. 38(11): p. 1505-1511.

34. Toledano, S., et al., Enzyme-triggered self-assembly of peptide hydrogels via reversed hydrolysis. J Am Chem Soc, 2006. 128(4): p. 1070-1.

35. Guler, M.O., et al., Presentation of RGDS Epitopes on Self-Assembled Nanofibers of Branched Peptide Amphiphiles. Biomacromolecules, 2006. 7(6): p. 1855-1863.

36. Guler, M.O., et al., Presentation and Recognition of Biotin on Nanofibers Formed by Branched Peptide Amphiphiles. Nano Letters, 2004. 5(2): p. 249-252.

37. Niece, K.L., et al., Self-Assembly Combining Two Bioactive Peptide-Amphiphile Molecules into Nanofibers by Electrostatic Attraction. Journal of the American Chemical Society, 2003. 125(24): p. 7146-7147.

38. Silva, G.A., et al., Selective Differentiation of Neural Progenitor Cells by High-Epitope Density Nanofibers. Science, 2004. 303(5662): p. 1352-1355.

39. Tysseling-Mattiace, V.M., et al., Self-Assembling Nanofibers Inhibit Glial Scar Formation and Promote Axon Elongation after Spinal Cord Injury. The Journal of Neuroscience, 2008. 28(14): p. 3814-3823.

40. Gore, T., et al., Self-Assembly of Model Collagen Peptide Amphiphile Langmuir, 2001. 17: p. 5352-5360.

41. Wang, K., J.D. Keasling, and S.J. Muller, Effects of the sequence and size of non-polar residues on self-assembly of amphiphilic peptides. International Journal of Biological Macromolecules, 2005. 36(4): p. 232-40. 
42. Xu, X.D., et al., Self-assembly behavior of peptide amphiphiles (PAs) with different length of hydrophobic alkyl tails. Colloids and Surfaces B Biointerfaces, 2010. 81(1): p. 329-35.

43. Han, S., et al., Self-assembly of short peptide amphiphiles: the cooperative effect of hydrophobic interaction and hydrogen bonding. Chemistry, 2011. 17(46): p. 13095-102.

44. Paramonov, S.E., H.-W. Jun, and J.D. Hartgerink, Modulation of Peptide - Amphiphile Nanofibers via Phospholipid Inclusions. Biomacromolecules, 2006. 7: p. 24-26.

45. Hartgerink, J.D., E. Beniash, and S.I. Stupp, Peptide-amphiphile nanofibers: A versatile scaffold for the preparation of self-assembling materials. Proceedings of the National Academy of Sciences, 2002. 99(8): p. 5133-5138.

46. $\mathrm{Xu}, \mathrm{H}$., et al., Hydrophobic-region-induced transitions in self-assembled peptide nanostructures. Langmuir, 2009. 25: p. 4115-4123.

47. Jun, H.W., et al., Enzyme-Mediated Degradation of Peptide-Amphiphile Nanofiber Networks. Advanced Materials, 2005. 17(21): p. 2612-2617.

48. Faul, C.F.J. and M. Antonietti, Ionic Self-Assembly: Facile Synthesis of Supramolecular Materials. Advanced Materials, 2003. 15(9): p. 673-683.

49. Stendahl, J.C., et al., Intermolecular Forces in the Self-Assembly of Peptide Amphiphile Nanofibers. Advanced Functional Materials, 2006. 16(4): p. 499-508.

50. Paramonov, S.E., H.W. Jun, and J.D. Hartgerink, Self-Assembly of Peptide - Amphiphile Nanofibers: The Roles of Hydrogen Bonding and Amphiphilic Packing. Journal of the American Chemical Society, 2006. 128: p. 7291-7298.

51. Dong, H., et al., Self-Assembly of Multidomain Peptides: Balancing Molecular Frustation Controls Conformation and Nanostructure. Journal of the American Chemical Society, 2007. 129: p. 12468-12472.

52. $\mathrm{Xu}, \mathrm{H}$. , et al., Twisted Nanotubes Formed from Ultrashort Amphiphilic Peptide I3K and Their Templating for the Fabrication of Silica Nanotubes. Chemistry of Materials, 2010. 22(18): p. 5165-5173.

53. Ganesh, S., S. Prakash, and R. Jayakumar, Spectroscopic investigation on gel-forming 6sheet assemblage of peptide derivatives. Biopolymers, 2003. 70(3): p. 346-354.

54. Zhang, S., et al., Spontaneous assembly of a self-complementary oligopeptide to form a stable macroscopic membrane. Proceedings of the National Academy of Sciences, 1993. 90(8): p. 3334-3338.

55. Shera, J.N. and X.S. Sun, Effect of peptide sequence on surface properties and selfassembly of an amphiphilic pH-responsive peptide. Biomacromolecules, 2009. 10: $\mathrm{p}$. 2446-2450.

56. Chen, K., et al., Neighbor effect on PPIl conformation in alanine peptides. J Am Chem Soc, 2005. 127(29): p. 10146-7.

57. Chen, K., Z. Liu, and N.R. Kallenbach, The polyproline II conformation in short alanine peptides is noncooperative. Proc Natl Acad Sci U S A, 2004. 101(43): p. 15352-7.

58. Reches, M. and E. Gazit, Casting Metal Nanowires Within Discrete Self-Assembled Peptide Nanotubes. Science, 2003. 300(5619): p. 625-627.

59. Yang, Z., et al., Small molecule hydrogels based on a class of antiinflammatory agents. Chemical Communications, 2004(2): p. 208-209.

60. Smith, A.M., et al., Fmoc-Diphenylalanine Self Assembles to a Hydrogel via a Novel Architecture Based on $\pi-\pi$ Interlocked B-Sheets. Advanced Materials, 2008. 20(1): p. 37-41.

61. Bakota, E.L., et al., Self-assembling multidomain peptide fibers with aromatic cores. Biomacromolecules, 2013. 14(5): p. 1370-8.

62. Ma, M., et al., Aromatic-Aromatic Interactions Induce the Self-Assembly of Pentapeptidic Derivatives in Water To Form Nanofibers and Supramolecular Hydrogels. Journal of the American Chemical Society, 2010. 132(8): p. 2719-2728. 
63. Bowerman, C.J. and B.L. Nilsson, A Reductive Trigger for Peptide Self-Assembly and Hydrogelation. Journal of the American Chemical Society, 2010. 132(28): p. 9526-9527.

64. Ramanathan, M., et al., Amphiphile nanoarchitectonics: from basic physical chemistry to advanced applications. Phys Chem Chem Phys, 2013. 15(26): p. 10580-611.

65. Qiu, F., Y. Chen, and X. Zhao, Comparative studies on the self-assembling behaviors of cationic and catanionic surfactant-like peptides. Journal of Colloid Interface Science 2009. 336(2): p. 477-84.

66. Meng, Q., et al., Tunable self-assembled peptide amphiphile nanostructures. Langmuir, 2012. 28(11): p. 5017-22.

67. Lee, O.-S., S.I. Stupp, and G.C. Schatz, Atomistic Molecular Dynamics Simulations of Peptide Amphiphile Self-Assembly into Cylindrical Nanofibers. Journal of the American Chemical Society, 2011. 133(10): p. 3677-3683.

68. Tsonchev, S., G.C. Schatz, and M.A. Ratner, Hydrophobically-driven self-assembly: a geometric packing analysis Nano Letters, 2003. 3(5): p. 623-626.

69. Tsonchev, S., G.C. Schatz, and M.A. Ratner, Electrostatically-Directed Self-Assembly of Cylindrical Peptide Amphiphile Nanostructures. The Journal of Physical Chemistry B, 2004. 108(26): p. 8817-8822.

70. Tsonchev, S., et al., On the structure and stability of self-assembled zwitterionic peptide amphiphiles: a theoretical study. Nano Letters, 2004. 4(3): p. 427-431.

71. Yu, T., O.S. Lee, and G.C. Schatz, Steered molecular dynamics studies of the potential of mean force for peptide amphiphile self-assembly into cylindrical nanofibers. The Journal of Physical Chemistry A, 2013. 117(32): p. 7453-7460.

72. $\mathrm{Yu}, \mathrm{T}$. and G.C. Schatz, Free energy profile and mechanism of self-assembly of peptide amphiphiles based on a collective assembly coordinate. The Journal of Physical Chemistry B, 2013. 117(30): p. 9004-9013.

73. $\mathrm{Yu}, \mathrm{T}$. and G.C. Schatz, Free-energy landscape for peptide amphiphile self-assembly: stepwise versus continuous assembly mechanisms. The Journal of Physical Chemistry B, 2013. 117(45): p. 14059-14064.

74. Theodoropoulou, M. and G.K. Stalla, Somatostatin receptors: from signaling to clinical practice. Frontiers in Neuroendocrinology, 2013. 34(3): p. 228-252.

75. Valery, C., et al., Biomimetic organization: Octapeptide self-assembly into nanotubes of viral capsid-like dimension. Proceedings of the National Academy of Sciences, 2003. 100(18): p. 10258-10262.

76. Valéry, C., et al., Self-Association Process of a Peptide in Solution: From B-Sheet Filaments to Large Embedded Nanotubes. Biophysical Journal, 2004. 86(4): p. 24842501.

77. Pandit, A., et al., Self-assembly of the octapeptide lanreotide and lanreotide-based derivatives: the role of the aromatic residues. Journal of Peptide Science, 2008. 14(1): p. 66-75.

78. Valéry, C., et al., Molecular Origin of the Self-Assembly of Lanreotide into Nanotubes: $A$ Mutational Approach. Biophysical Journal, 2008. 94(5): p. 1782-1795.

79. Pouget, E., et al., Elucidation of the Self-Assembly Pathway of Lanreotide Octapeptide into B-Sheet Nanotubes: Role of Two Stable Intermediates. Journal of American Chemical Society, 2010. 132: p. 4230-4241.

80. Valéry, C., F. Artzner, and M. Paternostre, Peptide nanotubes: molecular organisations, self-assembly mechanisms and applications. Soft Matter, 2011. 7(20): p. 9583-9594.

81. Freda, P.U., et al., Long-acting somatostatin analog therapy of acromegaly: a metaanalysis. J Clin Endocrinol Metab, 2005. 90(8): p. 4465-73.

82. Davis, M.E., et al., Local myocardial insulin-like growth factor 1 (IGF-1) delivery with biotinylated peptide nanofibers improves cell therapy for myocardial infarction. Proceedings of the National Academy of Sciences 2006. 103(21): p. 8155-60. 
83. Angeloni, N.L., et al., Regeneration of the cavernous nerve by Sonic hedgehog using aligned peptide amphiphile nanofibers. Biomaterials, 2011. 32(4): p. 1091-101.

84. Webber, M.J., et al., Controlled release of dexamethasone from peptide nanofiber gels to modulate inflammatory response. Biomaterials, 2012. 33(28): p. 6823-6832.

85. Soukasene, S., et al., Antitumor activity of peptide amphiphile nanofiber-encapsulated camptothecin. ACS Nano, 2011. 5(11): p. 9113-9121.

86. Lee, S.S., et al., Gel scaffolds of BMP-2-binding peptide amphiphile nanofibers for spinal arthrodesis. Adv Healthc Mater, 2015. 4(1): p. 131-41.

87. Guler, M.O., R.C. Claussen, and S.I. Stupp, Encapsulation of pyrene within selfassembled peptide amphiphile nanofibers. Journal of Materials Chemistry, 2005. 15(42): p. 4507.

88. Keller, S., et al., Membrane-mimetic nanocarriers formed by a dipalmitoylated cellpenetrating peptide. Angewandte Chemie International Edition, 2005. 44(33): p. 52525.

89. Accardo, A., et al., Nanostructures by self-assembling peptide amphiphile as potential selective drug carriers. Biopolymers, 2007. 88(2): p. 115-21.

90. van Hell, A.J., et al., Self-assembly of recombinant amphiphilic oligopeptides into vesicles. Biomacromolecules, 2007. 8: p. 2753-2761.

91. Kim, J.-K., et al., Self-assembling peptide amphiphile-based nanofiber gel for bioresponsive cisplatin delivery. Molecular Pharmaceutics, 2009. 6(3): p. 978-985.

92. Wiradharma, N., Y.W. Tong, and Y.-Y. Yang, Self-assembled oligopeptide nanostructures for co-delivery of drug and gene with synergistic therapeutic effect. Biomaterials, 2009. 30: p. 3100-3109.

93. Chow, L.W., et al., Self-assembling nanostructures to deliver angiogenic factors to pancreatic islets. Biomaterials, 2010. 31: p. 6154-6161.

94. Standley, S.M., et al., Induction of cancer cell death by self-assembling nanostructures incorporating a cytotoxic peptide. Cancer Research 2010. 70(8): p. 3020-3026.

95. Javali, N.M., et al., Fatty acid-RGD peptide amphiphile micelles as potential paclitaxel delivery carriers to alpha(v)beta(3) integrin overexpressing tumors. Pharmaceutical Research, 2012. 29(12): p. 3347-61.

96. de Bruyn Ouboter, D., et al., Multicompartment micelle-structured peptide nanoparticles: a new biocompatible gene- and drug-delivery tool. Journal of Biomedical Materials Research Part A, 2014. 102(4): p. 1155-63.

97. Berns, E.J., et al., Aligned neurite outgrowth and directed cell migration in selfassembled monodomain gels. Biomaterials, 2014. 35(1): p. 185-195.

98. Bond, C., Y. Tang, and C.A. Podlasek, Neural Influences on Sonic Hedgehog and Apoptosis in the Rat Penis. Biology of Reproduction, 2008. 78(5): p. 947-956.

99. Podlasek, C.A., et al., Regulation of Cavernous Nerve Injury-Induced Apoptosis by Sonic Hedgehog. Biology of Reproduction, 2007. 76(1): p. 19-28.

100. Matson, J.B. and S.I. Stupp, Drug release from hydrozone-containing peptide amphiphiles. Chemical Communications, 2011. 47(28): p. 7962-7964.

101. Jun, H.W., et al., Tuning the mechanical and bioresponsive properties of peptideamphiphile nanofiber networks. Journal of Biomaterials Science Polymer Edition, 2008. 19(5): p. 665-676.

102. Kunitake, T., Synthetic Bilayer Membranes: Molecular Design, Self-Organization, and Application. Angewandte Chemie International Edition in English, 1992. 31(6): p. 709726.

103. Cox, D., M. Brennan, and N. Moran, Integrins as therapeutic targets: lessons and opportunities. Nature Reviews Drug Discovery, 2010. 9(10): p. 804-820.

104. Wiradharma, N., Y.W. Tong, and Y.-Y. Yang, Design and evaluation of peptide amphiphiles with different hydrophobic blocks for simultaneous delivery of drugs and genes. Macromolecular Rapid Communications, 2010. 31: p. 1212-1217. 
105. Ray, G.B., I. Chakraborty, and S.P. Moulik, Pyrene absorption can be a convenient method for probing critical micellar concentration $(\mathrm{cm})$ and indexing micellar polarity. Journal of Colloid and Interface Science, 2006. 294(248-254).

106. de Bruyn Outober, D., et al., Mulicompartment micelle-structured peptide nanoparticles: a new biocompatible gene-and drug-delivery tool. Journal of Biomedical Materials Research Part A, 2014. 102A: p. 1155-1163. 